\title{
Thermal Properties of Ethanol Organosolv Lignin Depending on Its Structure
}

\author{
June-Ho Choi, Seong-Min Cho, Jong-Chan Kim, Sang-Woo Park, Young-Min Cho, Bonwook Koo, \\ Hyo Won Kwak, and In-Gyu Choi*
}

Cite This: ACS Omega 2021, 6, 1534-1546

Read Online

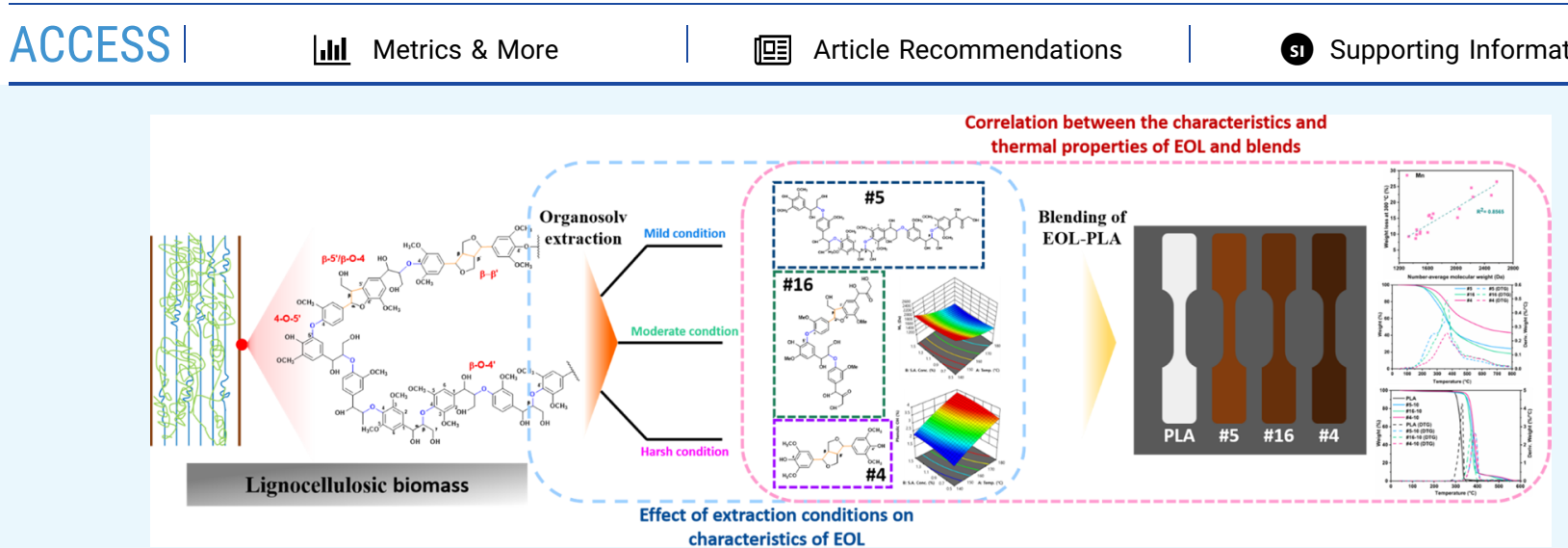

ABSTRACT: In general, lignin exhibits unpredictable and nonuniform thermal properties due to the structural variations caused by the extraction processes. Therefore, a systematic understanding of the correlation between the extraction conditions, structural characteristics, and properties is indispensable for the commercial utilization of lignin. In this study, the effect of extraction conditions on the structural characteristics of ethanol organosolv lignin (EOL) was investigated by response surface methodology. The structural characteristics of EOL (molecular weight, hydroxyl content, and intramolecular coupling structure) were significantly affected by the extraction conditions (temperature, sulfuric acid concentration, and ethanol concentration). In addition, the correlation between the structural characteristics and thermal properties of the extracted EOLs was estimated. The relevant correlations between the structural characteristics and thermal properties were determined. In particular, EOLs that had a low molecular weight, high phenolic hydroxyl content, and low aryl-ether linkage content exhibited prominent thermal properties in terms of their initial decomposition rate and a high glass transition temperature, $T_{\mathrm{g}}$. Correspondingly, EOL-PLA blends prepared using three EOL types exhibited improved thermal properties (starting point of thermal decomposition and maximum decomposition temperature) compared to neat PLA and had thermal decomposition behaviors coincident with the thermal properties of the constituent EOLs.

\section{INTRODUCTION}

Recently, fine plastics have emerged as contributors to significant environmental issues, and the problem of microplastics is expected to become increasingly serious as the amount of plastics increases. According to www.Statista.com, global plastic production has increased steadily for decades, reaching 359 million metric tons in 2018. ${ }^{1}$ Correspondingly, the amount of plastic waste generation has steadily increased, and only part of this waste is recycled, with the rest incinerated or delivered to landfills. Plastic incineration can lead to air pollution from the harmful gases generated during the process. In addition, petrochemical-based plastics take a long time to decompose and can cause soil contamination when deposited in landfills. ${ }^{2}$

Biodegradable plastics, which are defined as plastics that can be decomposed into water and carbon dioxide by microorganisms in soil or water, have attracted much attention as alternative materials and solutions to ameliorate the environmental pollution caused by petroleum-based plastics in response to the depletion of petroleum resources and environmental pollution. However, even though most biodegradable plastics have the advantage of being biodegradable, there are some drawbacks to their physical properties, such as strength and elongation. Moreover, their thermal properties, including thermal stability and heat resistance, are weaker compared to that of conventional petrochemical-based plastics, resulting in poor processability. ${ }^{3}$ Furthermore,

Received: November 1, 2020

Accepted: December 29, 2020

Published: January 7, 2021 
Table 1. Yield of EOL and Monomeric Sugars in Liquid Hydrolysate after Extraction of EOL, Depending on the Conditions Designed for RSM Analysis

\begin{tabular}{|c|c|c|c|c|c|c|c|}
\hline \multirow[b]{3}{*}{ std } & \multirow{2}{*}{\multicolumn{3}{|c|}{ variables }} & \multicolumn{4}{|c|}{ yield (\%*) } \\
\hline & & & & \multirow[t]{2}{*}{ EOL } & \multicolumn{3}{|c|}{ liquid hydrolysate } \\
\hline & reaction temperature $\left({ }^{\circ} \mathrm{C}\right)$ & $\mathrm{H}_{2} \mathrm{SO}_{4}$ concentration $(\%(\mathrm{w} / \mathrm{v}))$ & EtOH concentration $(\%(v / v))$ & & glucose & XMG & arabinose \\
\hline 3 & 140 & 1.5 & 40 & 10.95 & 2.01 & 12.69 & 2.2 \\
\hline 7 & 140 & 1.5 & 80 & 13.45 & 1.22 & 11.51 & 1.85 \\
\hline 1 & 140 & 0.5 & 40 & 11.05 & 1.53 & 11.05 & 1.41 \\
\hline 5 & 140 & 0.5 & 80 & 11.68 & 1.36 & 9.84 & 1.35 \\
\hline 16 & 160 & 1 & 60 & 16.55 & 3.95 & 13.47 & 3.46 \\
\hline 17 & 160 & 1 & 60 & 16.57 & 4.17 & 13.44 & 3.66 \\
\hline 2 & 180 & 0.5 & 40 & 17.62 & 7.65 & 10.98 & 5.45 \\
\hline 10 & 193.6 & 1 & 60 & 22.79 & 18.23 & 2.09 & 7.9 \\
\hline 13 & 160 & 1 & 26.4 & 9.79 & 4.08 & 13.57 & 3.42 \\
\hline 9 & 126.4 & 1 & 60 & 6.9 & 1.03 & 6.85 & 0.82 \\
\hline 14 & 160 & 1 & 93.6 & 14.24 & 4.41 & 12.25 & 3.56 \\
\hline 12 & 160 & 1.84 & 60 & 16.13 & 4.93 & 12.64 & 4.31 \\
\hline 4 & 180 & 1.5 & 40 & 19.33 & 14.67 & 4.96 & 8.47 \\
\hline 11 & 160 & 0.16 & 60 & 16.38 & 1.67 & 11.93 & 1.51 \\
\hline 8 & 180 & 1.5 & 80 & 21.81 & 18.52 & 4.32 & 8.46 \\
\hline 15 & 160 & 1 & 60 & 16.38 & 4.32 & 12.2 & 3.94 \\
\hline 6 & 180 & 0.5 & 80 & 17.92 & 11.85 & 9.56 & 6.73 \\
\hline
\end{tabular}

biopolyesters have lower price competitiveness than conventional plastics due to their unoptimized processes, the high price of raw materials, and the small-scale market size., Therefore, enhancing the physical properties of biopolyesters and improving their price competitiveness are emerging as major issues for commercialization. To satisfy both goals, several efforts have been attempted to adjust the physical and thermal properties by manufacturing a fully biomass-based biopolyester blend using components of lignocellulosic biomass that has high price competitiveness, biodegradability, and unique properties.

Lignin, a naturally occurring polymer, can be produced at a relatively low cost due to its simple manufacturing process compared to that of other synthesized polymers and has the advantages of excellent biocompatibility and biodegradability. ${ }^{7}$ Accounting for approximately $20-30 \%$ of lignocellulosic biomass, lignin is the second most abundant naturally occurring polymer in the world. Lignin has the potential to be used as an additive or a precursor of bioplastics to impart functionality to the bioplastics. ${ }^{7}$ Lignin has unique properties, such as thermal stability, antioxidant, antifungal, and antibacterial activities, and a rigid chemical structure. ${ }^{8}$ In particular, the thermal properties of lignin, which are derived from its inherent structural properties, can be remarkable advantages for the thermal vulnerability of biopolyesters. ${ }^{9}$

On the other hand, lignin macromolecules have complex bonding structures and functional groups, and these structural characteristics lead to unique properties. Lignin macromolecules have various functional groups in their structure, including hydroxyl groups, methoxy groups, carbonyl groups, and carboxyl groups. Among these functional groups, the hydroxyl group content is predominant, and hydroxyl groups can be roughly categorized into phenolic hydroxyl groups and aliphatic hydroxyl groups. Phenolic hydroxyl group and aliphatic hydroxyl group contents are strongly influenced by the extraction conditions. The hydroxyl groups of lignin cause intra- and intermolecular hydrogen bonding, resulting in the various physical and thermal properties of lignin. Hydrogen bonds can cause steric hindrance by reducing the accessibility of the functional groups in lignin. ${ }^{10}$ The phenolic structures in lignin provide thermal stability at high temperatures. ${ }^{11}$ Interestingly, lignin has both thermoplastic and thermosetting properties due to its amorphous chemical structure and intermolecular and intramolecular interactions. ${ }^{12}$ Lignin macromolecules cross-linked in three dimensions have the characteristics of thermoset materials. ${ }^{13}$ In this way, the properties of lignin are greatly influenced by the structural characteristics of lignin.

However, lignin produced by a delignification process has a nonuniform structure because of the heterogeneous structure, making it difficult to predict its physicochemical properties. ${ }^{14}$ The structural characteristics of lignin greatly depend on the extraction conditions. During processing, lignin macromolecules, which have complex inter- and intramolecular bonds within the biomass, are partially depolymerized and converted into smaller lignin fractions. ${ }^{15}$ In addition, the converted lignin fractions can be recondensed by functional groups, depending on the process conditions, forming stronger bonds. ${ }^{16}$ Therefore, it is necessary to investigate the structural characteristics of organosolv lignin according to the extraction conditions. Furthermore, the relationship between the structural characteristics of lignin and the physical and thermal properties of lignin or lignin-biopolyester blends is important to improve the potential commercial utilization of lignin.

\section{RESULTS AND DISCUSSION}

Structural Characteristics of Ethanol Organosolv Lignin Depending on the Extraction Conditions. For the effective utilization of lignin in bioplastic applications, the properties of bioplastics containing lignin have to be predicted. In the same context, it is important to determine the properties of the lignin feedstock to select and prepare suitable lignin that exhibits the desired properties. The physicochemical properties of lignin macromolecules are influenced by their structural characteristics, such as intramolecular bonds, functional groups, and molecular weight. The structures of the lignin macromolecules are most affected by the extraction method. 
(a)
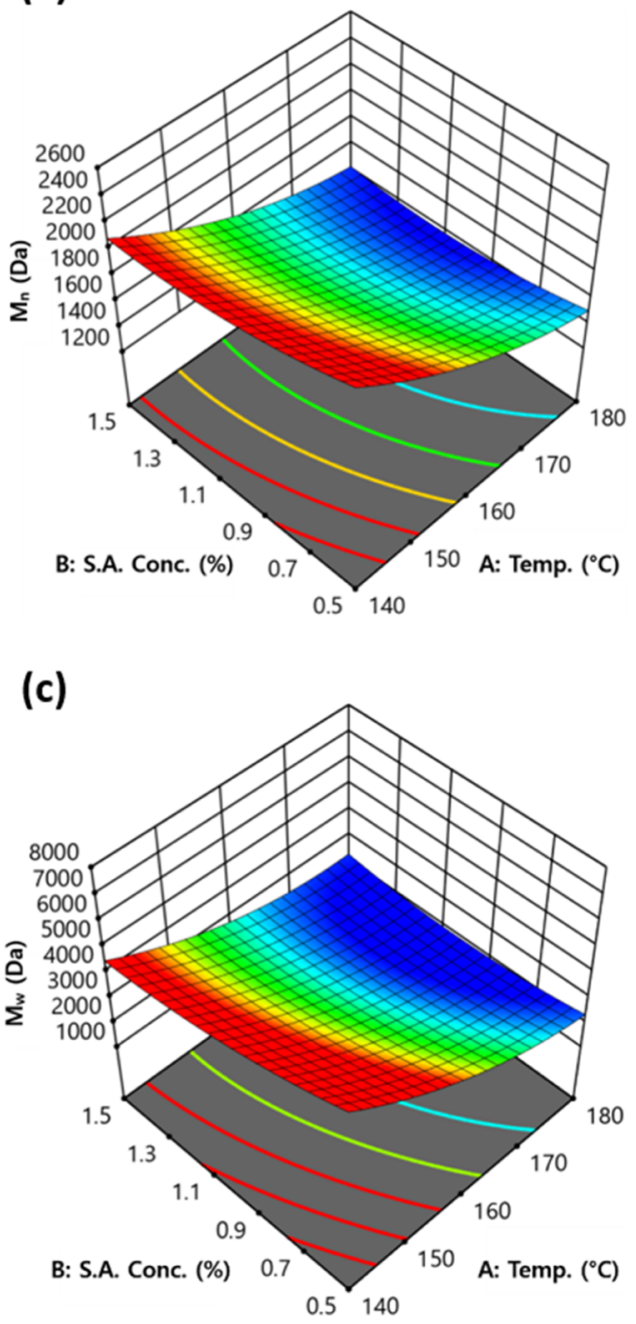

(b)

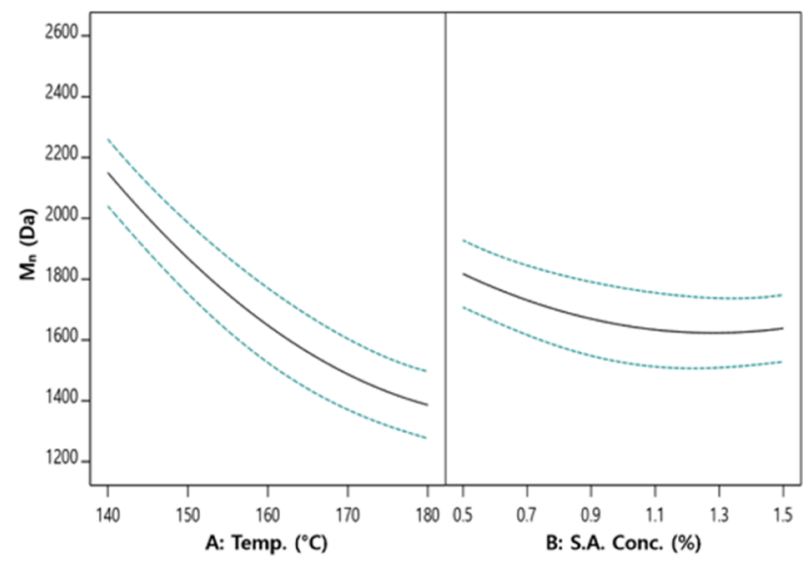

(d)

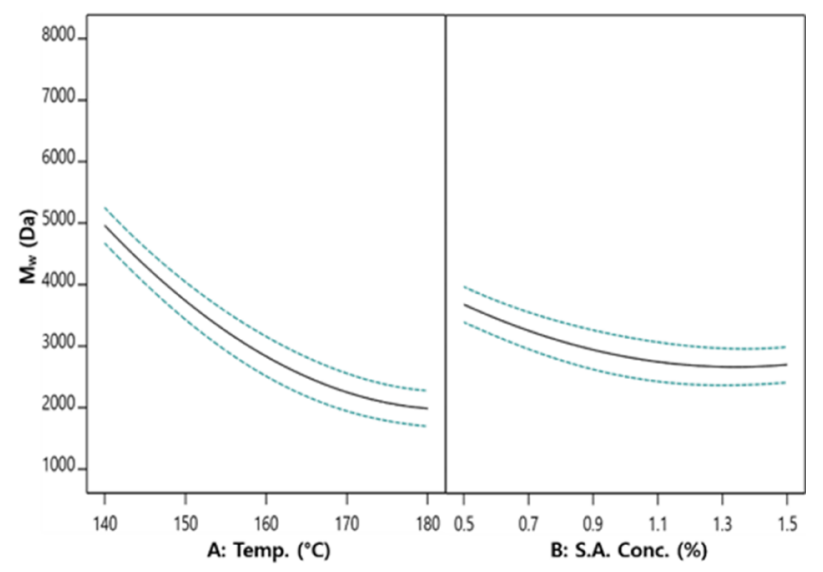

Figure 1. Effect of the extraction conditions on EOL molecular weight. (a) Contour plot of the RSM for the number-average molecular weight $\left(M_{\mathrm{n}}\right)$ model. (b) One-factor plots of $M_{\mathrm{n}}$ vs significant variables. (c) Contour plot of the RSM analysis for the weight-average molecular weight $\left(M_{\mathrm{w}}\right)$ model. (d) One-factor plots of $M_{\mathrm{w}}$ vs significant variables.

However, the structure can be partially adjusted depending on the extraction conditions, even when the same extraction methods are used. Therefore, it is necessary to specifically investigate how the structure of lignin changes as the extraction conditions are controlled. During the organosolv pretreatment, decomposition and recondensation of organosolv lignin occur simultaneously, and this reaction behavior is greatly affected by the reaction conditions.

Mass Balance of Raw Materials for the Ethanol Organosolv Extraction. Lignin has traditionally been produced in large quantities as a byproduct of the pulp industry, and recently, as part of the biorefinery, lignin derivatives can be generated in the biofuel production process. ${ }^{10}$ Therefore, considering economic feasibility, it is necessary to prevent the undesirable decomposition of cellulose or hemicellulose, which is a major product of biomass in the lignin extraction process. Table 1 shows the yield of ethanol organosolv lignin (EOL) and monomeric sugars in liquid hydrolysate after the extraction of EOL, depending on the conditions designed for response surface methodology (RSM) analysis.

The yield of EOL was 22.79, 21.81, and 19.33 in \#10, \#8, and \#4, respectively, indicating that a large amount of EOL was produced under severe extraction conditions. High content of glucose in the liquid phase was also detected under conditions \#10, \#8, and \#4. The glucose cloud dissolved in the liquid hydrolysate can be partially derived from glucuronoxylan, but most of it is derived from cellulose. ${ }^{17}$ Therefore, the loss of glucose in the organosolv extraction process cannot be completely prevented, but excessive loss of glucose needs to be avoided. On the other hand, the XMG content showed a high value under relatively moderate conditions, including central point (\#15, \#16, and \#17), and a low value under mild and harsh conditions. During the organosolv extraction, acid hydrolysis of hemicellulose and conversion of free sugars in liquid hydrolysate occur simultaneously. ${ }^{18}$ Under harsh conditions, the conversion of free sugar is accelerated, and the XMG content in the liquid hydrolysate decreases. However, in order to maximize the solubility of hemicellulose, it is important to obtain it in the form of oligomeric or monomeric sugars, a key intermediate of various high-valueadded chemicals, without further decomposition. Therefore, in this study, based on the preliminary experimental results, the condition in which a large amount of XMG can be obtained is selected as the central point to design the experimental condition for RSM analysis. 
(a)

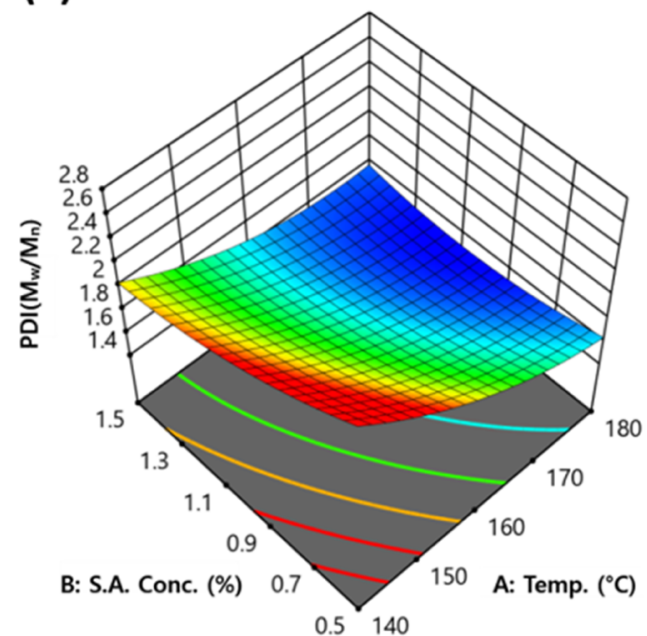

(b)

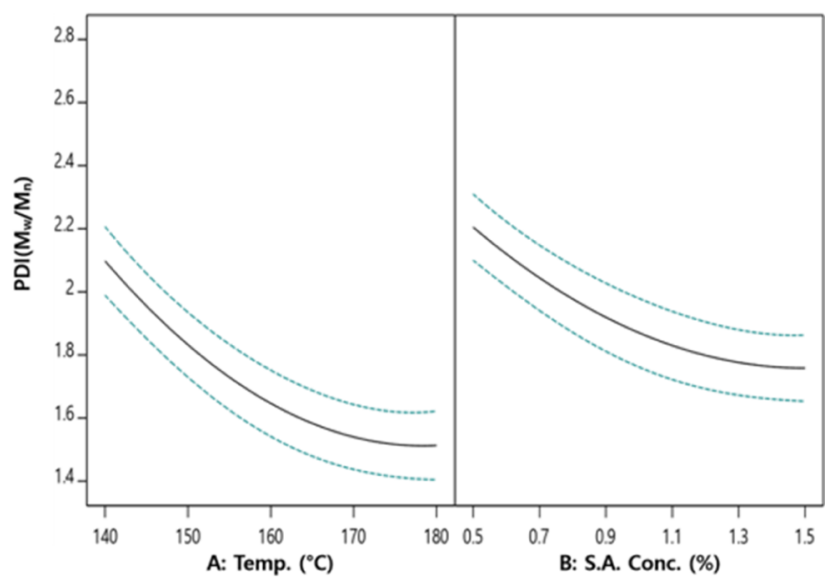

Figure 2. Effect of the extraction conditions on the EOL PDI. (a) Contour plot of the RSM for the PDI model. (b) One-factor plots of PDI versus significant variables.

(a)

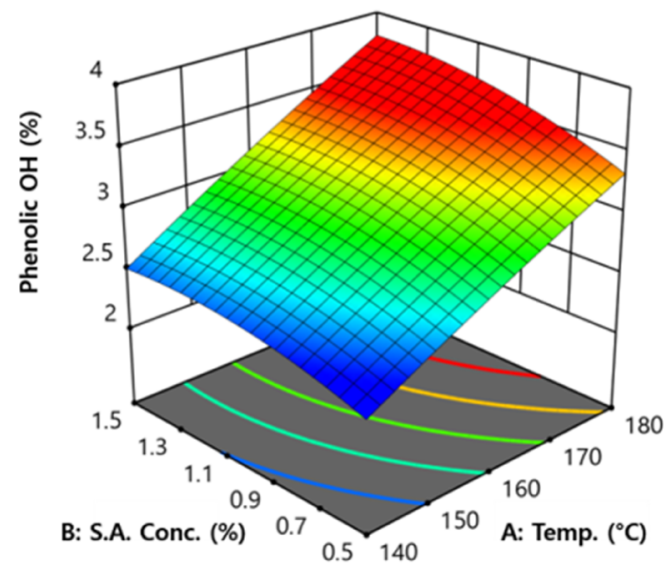

(c)

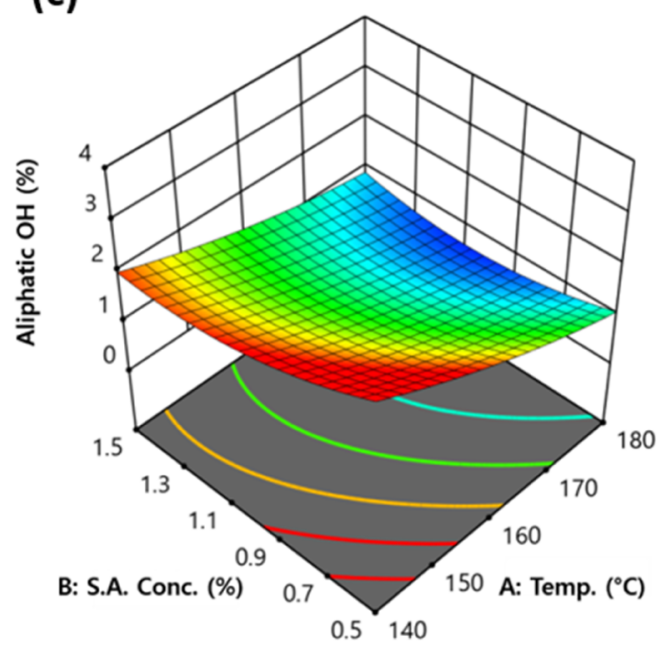

(b)

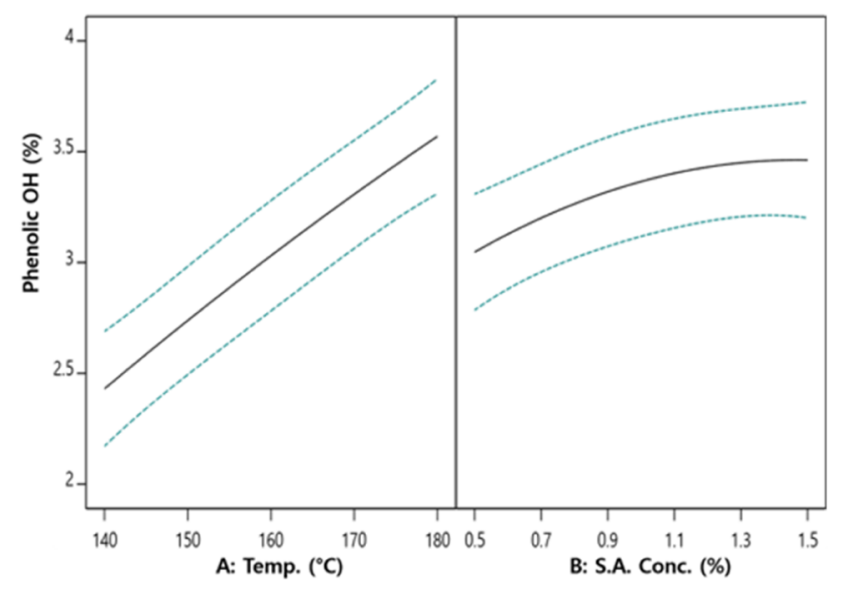

(d)

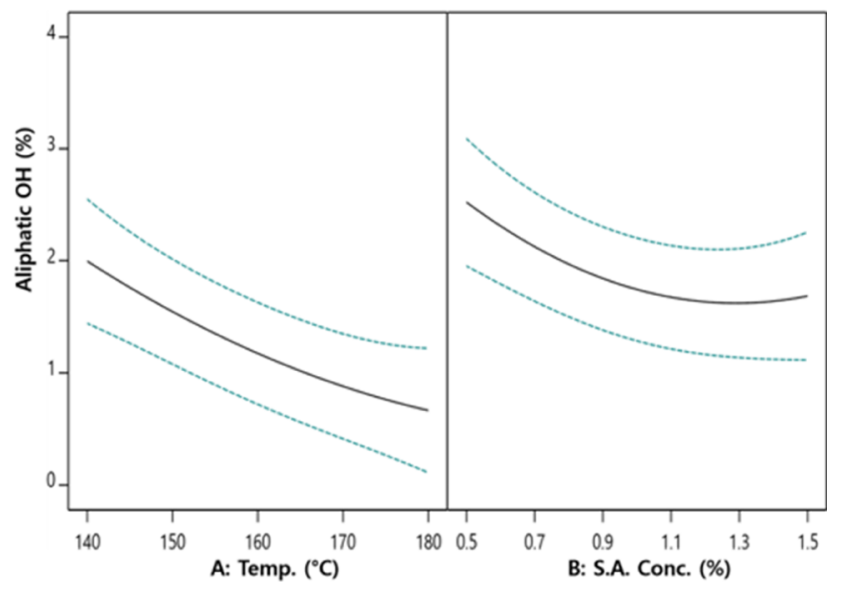

Figure 3. Effect of the extraction conditions on the EOL hydroxyl group content. (a) Contour plot of the RSM for the phenolic hydroxyl group (Phenolic OH) model. (b) One-factor plots of the Phenolic OH versus significant variables. (c) Contour plot of the RSM for the aliphatic hydroxyl group (Aliphatic $\mathrm{OH}$ ) model. (d) One-factor plots of the Aliphatic $\mathrm{OH}$ versus significant variables. 
Molecular Weight and Polydispersity Index. In general, EOL has a molecular weight in the range of 500$5000 \mathrm{Da}$, and the molecular weight of EOL is affected by the organosolv pretreatment reaction conditions. ${ }^{19}$ The results of the RSM analysis used to investigate the effect of the extraction conditions on the molecular weight of EOL are shown in Table $\mathrm{S} 1$ and Figure 1.

Statistical information of the molecular weight models is shown in Supporting Information (Table S1). The F-value of the molecular weight model $\left(M_{\mathrm{n}}=33.04, M_{\mathrm{w}}=82.8\right)$ implies that the model is significant. $P$-values less than 0.0500 indicate that the model terms are significant. In this case, A (reaction temperature) and B (sulfuric acid concentration) are significant model terms. Within the range covered by this model, number-average molecular weight of lignin tended to decrease with increasing reaction temperature and sulfuric acid concentration (Figure 1b). During the process of ethanol organosolv extraction, an increase in the reaction temperature and sulfuric acid concentration stimulated extensive decomposition of aryl-ether bonds, which are easily cleaved under acidic conditions. The decomposition of aryl-ether bonds converts lignin macromolecules into smaller fractions of the same molecular weight. ${ }^{20}$ Excessive severity of the extraction conditions may decompose lignin into small fractions that cannot be recovered. In addition, recondensation between phenolic compounds derived from lignin macromolecules, including a benzyl carbocation reaction and an $\alpha$-position condensation, can occur simultaneously, resulting in a rigid structure of lignin and an increase in the polydispersity. ${ }^{15,16}$ However, as the maximum point was not observed in the extraction condition range adopted in this study, excessive decomposition or condensation was assumed to have not been induced. Interestingly, even for the same extraction method, the molecular weight of lignin was distributed over a wide range, depending on the extraction conditions. In the case of $M_{\mathrm{w}}$, the lignin extracted under harsh conditions (X1: $180{ }^{\circ} \mathrm{C}$, X2: $1.5 \%$, and X3: $40 \%$ ) was approximately $2200 \mathrm{Da}$, while the lignin extracted under mild conditions was approximately of 6200 Da.

Furthermore, Table S2 and Figure 2 show the effect of the extraction conditions on the polydispersity index (PDI) of EOL. As shown in Table S2, the PDI model was found to be significant, according to the statistics, and the reaction temperature and sulfuric acid concentration were significant model terms. PDI of EOL tended to decrease with increasing reaction temperature and sulfuric acid concentration (Figure 2). As the severity of the extraction conditions increased, lignin macromolecules with higher molecular weights and containing a large number of aryl-ether bonds in the structure depolymerized more often than lignin molecules with smaller molecular weights. ${ }^{21,22}$ For this reason, $M_{\mathrm{w}}$ decreased more significantly than $M_{n}$, leading to a decrease in the PDI. In this model, the PDI was approximately 2.5 under mild extraction conditions and decreased to approximately 1.5 as the extraction conditions became severe. The EOL obtained by adjusting the extraction conditions had a narrow PDI value compared to other technical lignins, which guarantees high potential for industrial application. ${ }^{23}$

Hydroxyl Group Content. Lignin macromolecules have various functional groups in their structure, including hydroxyl groups, methoxy groups, carbonyl groups, and carboxyl groups. Among these groups, the hydroxyl group content is predominant, and hydroxyl groups can be roughly categorized into phenolic hydroxyl groups and aliphatic hydroxyl groups. Phenolic hydroxyl group and aliphatic hydroxyl group content levels are strongly influenced by the extraction conditions. These lignin hydroxyl groups cause intra- and intermolecular hydrogen bonding, resulting in different physical and thermal properties of lignin. ${ }^{10}$ Table S3 and Figure 3 describe the effect of the extraction conditions on the phenolic and aliphatic hydroxyl contents of the EOL.

As shown in Table S3, F-values of the phenolic hydroxyl group and aliphatic hydroxyl group model were 18.10 and 13.09, respectively, and $P$-values were 0.0005 and 0.0013 , respectively, which indicates that these models are significant within the set range. The extraction temperature and sulfuric acid concentration had a low $P$-value $(<0.5)$, which indicates that these two independent variables are powerful model terms. In the contour plot results, the phenolic hydroxyl group content increased with increasing reaction temperature and sulfuric acid concentration. Under the extraction process with high temperature and acidic conditions, $\beta$-O- 4 bonds, which are the dominant chemical coupling structure of EOL, are actively cleaved by a nucleophilic substitution reaction, resulting in an increase in the phenolic hydroxyl group content. $^{15,24}$

On the other hand, the content of the aliphatic hydroxyl group decreased as the temperature of the extraction increased, showing an opposite tendency to that of the phenolic hydroxyl group. In general, a solvent molecule including a methoxy group or ethoxy group is introduced as a nucleophile instead of a hydroxyl group at the electrophilic site of the lignin side chain produced by the decomposition of aryl-ether bonds during the organosolv extraction process. ${ }^{25}$ Moreover, as the severity of the extraction conditions increased, dehydration and demethoxylation reactions were accelerated in the lignin side chain, along with cleavage of side chains, including the $\mathrm{C} \alpha-\mathrm{C} \beta$ and $\mathrm{C} \beta-\mathrm{C} \gamma$ linkages. ${ }^{26,27}$ Therefore, the cleavage of ether bonds in the process of organic solvent extraction is accompanied by the inactivation of side chain functional groups.

Figure 4 illustrates ${ }^{31} \mathrm{P}$ nuclear magnetic resonance (NMR) spectroscopy of three EOL types (\#5: EOL extracted under mild condition, \#16: EOL extracted under moderate condition,

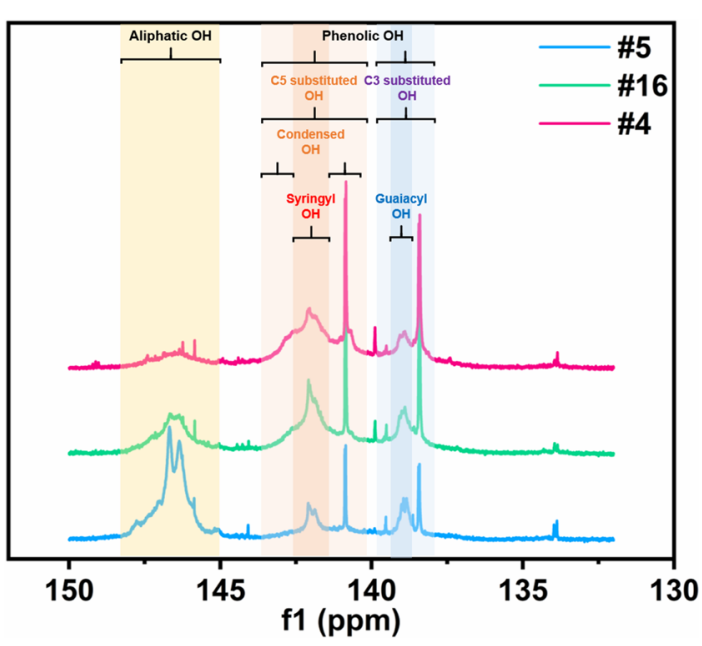

Figure 4. ${ }^{31} \mathrm{P}$ NMR spectrum of three EOL types (\#5: EOL extracted under mild conditions, \#16: EOL extracted under moderate conditions, and \#4: EOL extracted under harsh conditions). 
Table 2. Quantification of Aliphatic and Phenolic Hydroxyl Groups of Three EOL Types

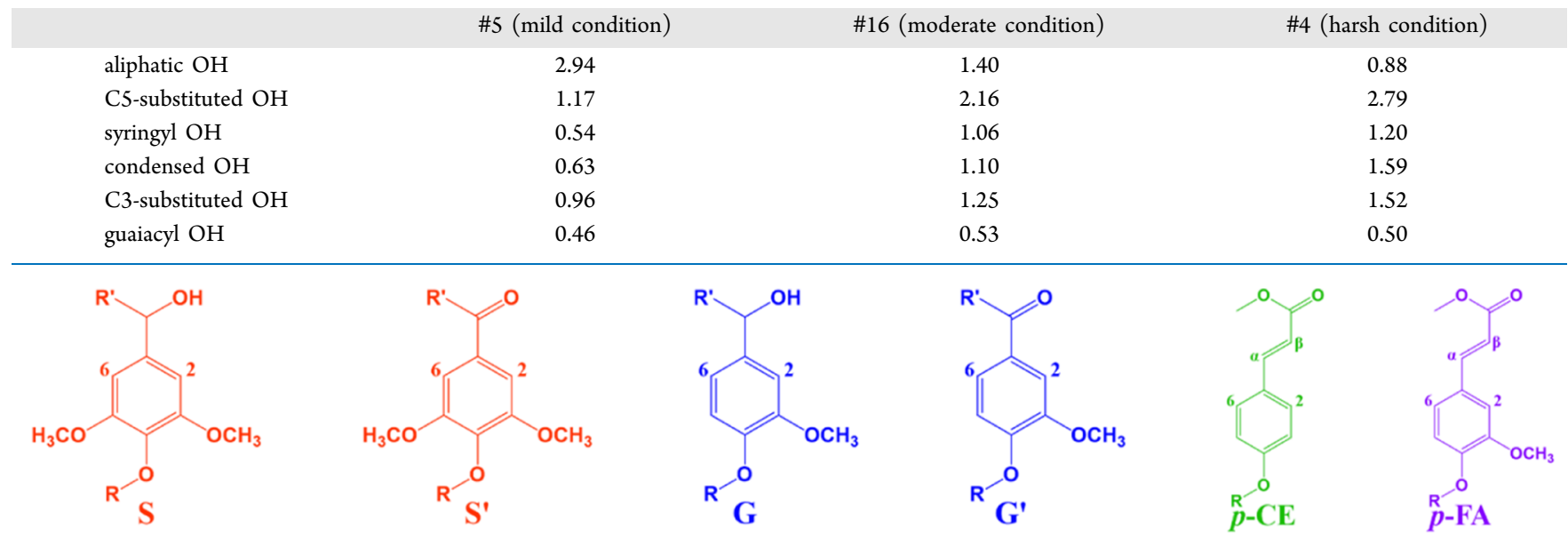

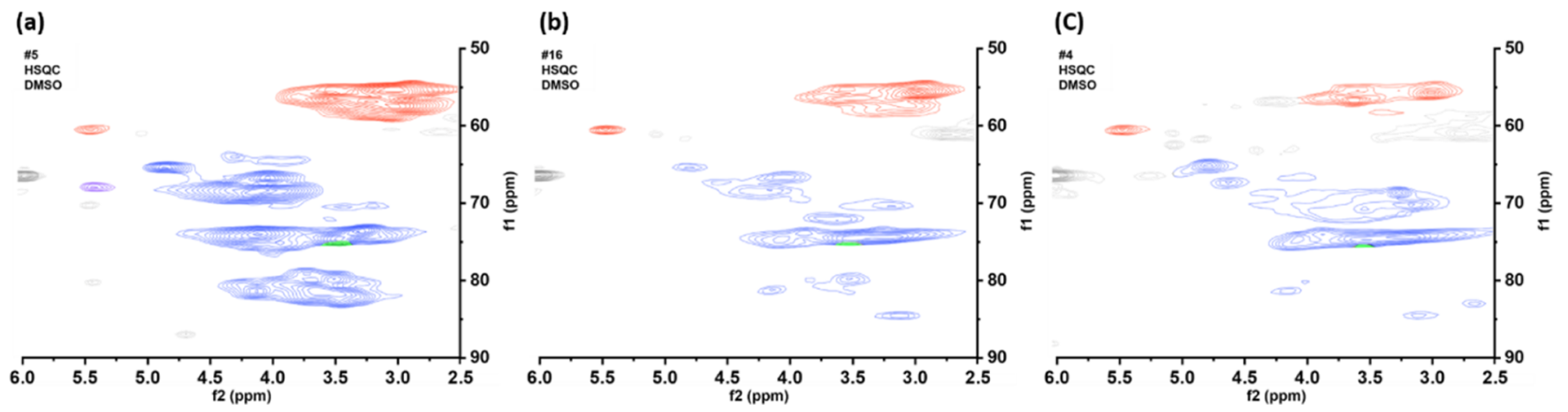

Figure 5. Aromatic/unsaturated $(\delta \mathrm{C} / \delta \mathrm{H} 100-125 / 6.5-7.5)$ regions in the $2 \mathrm{D}-\mathrm{HSQC}$ NMR spectra of the EOL, with the main lignin aromatic structures identified. (a) EOL \#5 extracted under mild conditions. (b) EOL \#16 extracted under moderate conditions. (c) EOL \#4 extracted under harsh conditions.

and \#4: EOL extracted under harsh condition). Intensity of the peaks corresponding to aliphatic hydroxyl groups showed a tendency to decrease as the severity of the extraction conditions increased. On the contrary, the peak intensity of phenolic hydroxyl groups including $\mathrm{C} 5$-substituted $\mathrm{OH}$ and $\mathrm{C} 3$-substituted $\mathrm{OH}$ tended to increase as the severity of the extraction conditions increased. In particular, as shown in the quantification table of the phenolic hydroxyl group region, the peak intensity of the condensed $\mathrm{OH}$ region, which is a $\mathrm{C5}$ substituted $\mathrm{OH}$ region excluding syringyl $\mathrm{OH}$, increased remarkably as the severity of the extraction conditions increased (Table 2). In the ethanol organosolv extraction process, aryl-ether decomposition of the lignin and recondensation of the produced lignin fragments are achieved simultaneously, and recondensation is promoted under harsh conditions, resulting in strengthened peaks of C5-substituted $\mathrm{OH}$.

Intramolecular Coupling Structure. Lignin has diverse intramolecular bonds in its chemical structure, including $\beta$-O-4 (aryl ether), $\alpha$-O-4 (aryl ether), $\beta$-5 ( $\beta$-5, phenylcoumaran), 55 (biphenyl), 4-O-5 (diaryl ether), $\beta$-1 (1,2-diarylpropane), and $\beta-\beta$ (resinol) bonds. ${ }^{28}$ The linkage type of the intermolecular bonds affects the properties of the lignin. In addition, the diversity of the intermolecular bonds in lignin makes it difficult to extract lignin from lignocellulose as a uniform structure. These intramolecular coupling structures of the organosolv lignin also vary depending on the extraction conditions. In this study, to investigate the effect of extraction conditions on the intramolecular coupling structure, two- dimensional heteronuclear single quantum coherence (2DHSQC) NMR analysis of three EOL types obtained from extraction conditions of different severities, was performed. In addition, the ${ }^{31} \mathrm{P}$ NMR spectroscopy was referred for the determination of the $S / G$ ratio. Figure 5 describes the results of the 2D-HSQC NMR analysis of three EOL types produced by extraction conditions of different severities. Table 3 summarizes the quantification of the side chain units connected by ether linkages and the $S / G$ unit ratio in the EOL structure.

As shown in Figure 5, guaiacyl (G) and syringyl (S) units with substructures were observed in EOL aromatic regions. As the severity of the extraction conditions increased, the intensity of the spectrum of the $\mathrm{G}$ unit region of the EOL was reduced compared to that of the $S$ unit region, which resulted in a

Table 3. Quantification of Oxygenated Aliphatic Side Chain Units Connected by Ether Linkages and the S/G Unit Ratio of Three EOL Types

$\begin{array}{lccc} & \begin{array}{c}\# 5 \\ \text { (mild condition) }\end{array} & \begin{array}{c}\# 16 \\ \text { (moderate condition) }\end{array} & \begin{array}{c}\# 4 \\ \text { (harsh condition) }\end{array} \\ \beta-\mathrm{O}-4 & 21.90 & 9.03 & 2.98 \\ \beta-\beta & 9.29 & 7.98 & 4.99 \\ \beta-5 & 5.28 & 2.71 & 0.39 \\ \begin{array}{c}\text { total ether } \\ \text { linkages }\end{array} & 41.47 & 35.72 & 16.37 \\ \begin{array}{c}\text { S/G unit } \\ \text { ratio }\end{array} & 1.22 & 1.73 & 1.83\end{array}$




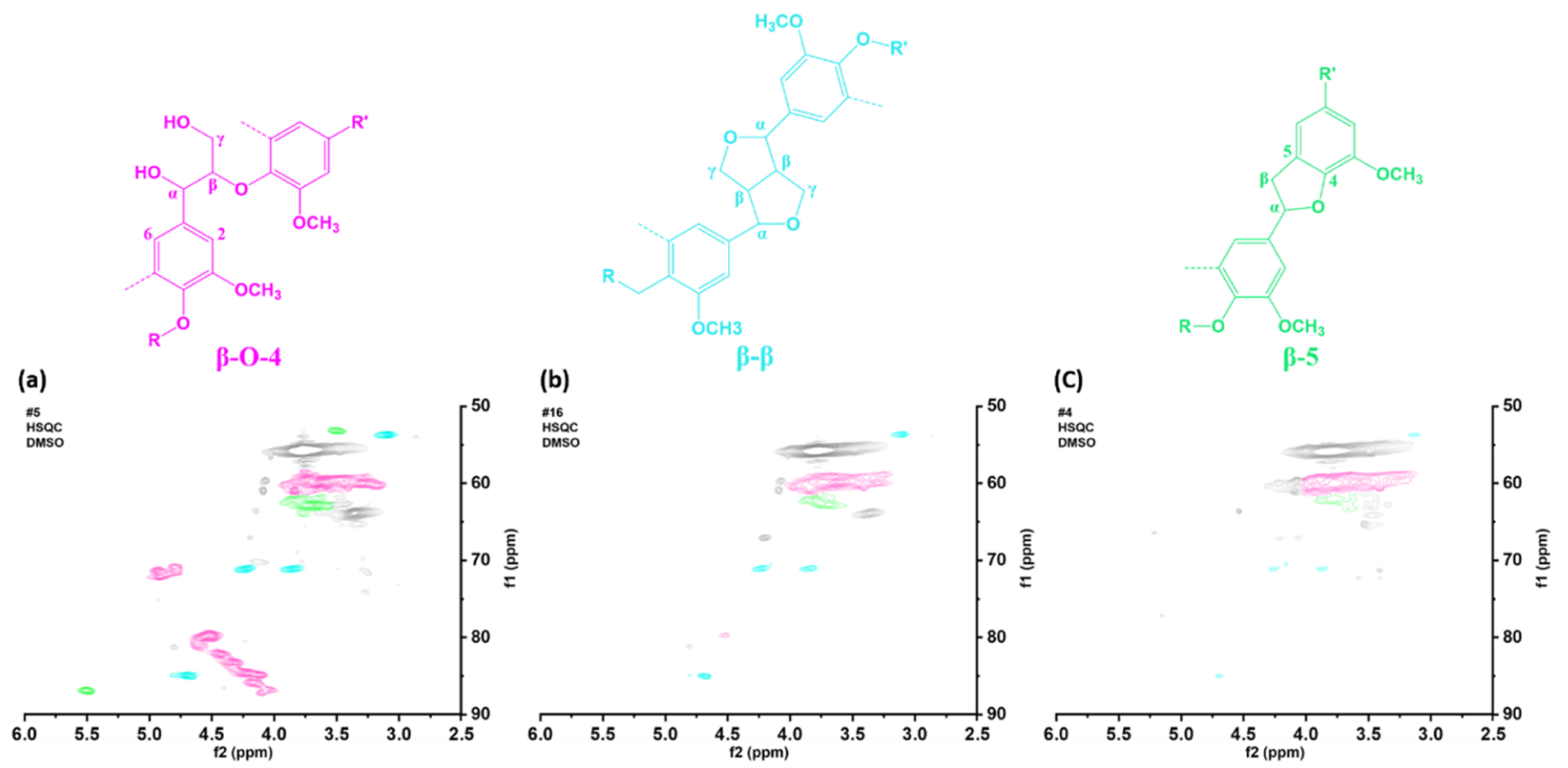

Figure 6. Oxygenated aliphatic side chain $(\delta \mathrm{C} / \delta \mathrm{H} 50-90 / 2.5-6.0)$ regions in the $2 \mathrm{D}-\mathrm{HSQC}$ NMR spectra of EOL, with the main lignin side chain structures identified. (a) EOL \#5 extracted under mild conditions. (b) EOL \#16 extracted under moderate conditions. (c) EOL \#4 extracted under harsh conditions.

(a)

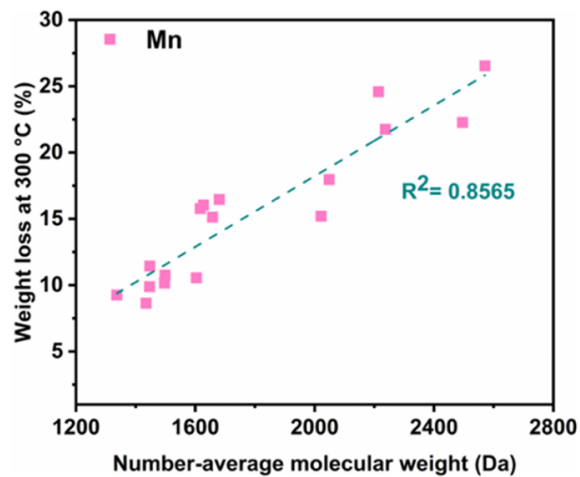

(c)

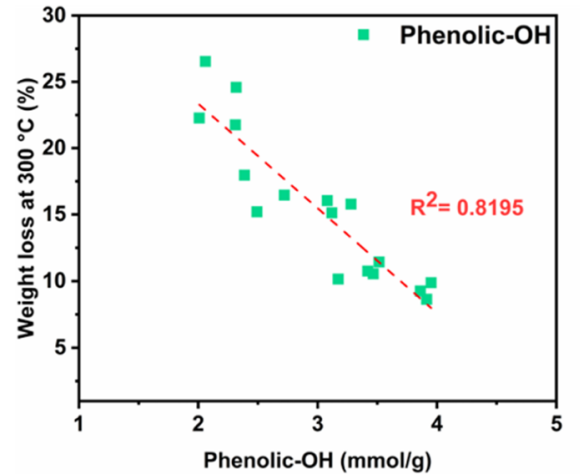

(b)

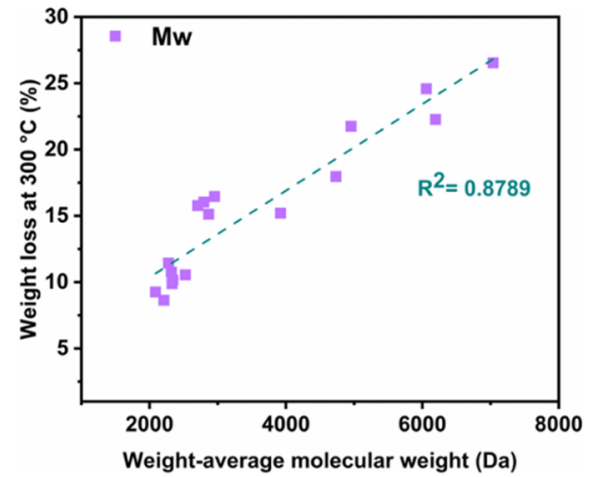

(d)

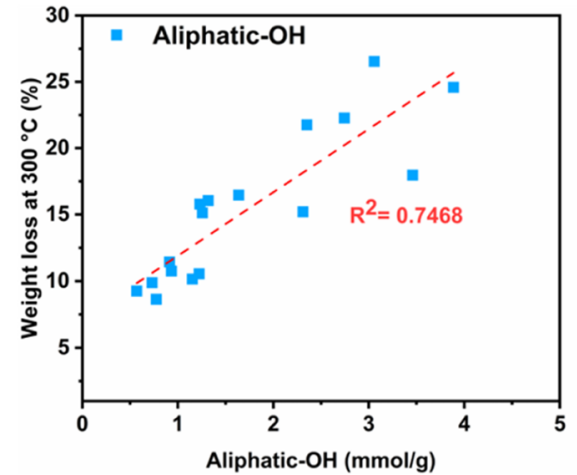

Figure 7. Correlation plot for weight loss at $300{ }^{\circ} \mathrm{C}$ vs structural characteristics. (a) $M_{\mathrm{n}}$. (b) $M_{\mathrm{w}}$. (c) Phenolic OH. (d) Aliphatic OH.

higher S/G unit ratio (Table 3). The G unit has a chemical structure in which one ortho position is substituted with a methoxyl group, while the $S$ unit has a chemical structure in which both ortho positions are substituted with methoxyl groups. The high degree of substitution of $S$ units means that all of the two active sites are coupling with another aromatic moiety. ${ }^{10}$ In this respect, the $S$ unit moiety has a relatively less condensed structure and contains a structure composed of aryl-ether bonds that are more easily decomposed under acidic conditions than the $\mathrm{G}$ unit moiety with the $\mathrm{C}-\mathrm{C}$ bond introduced at the C5 position. ${ }^{29}$ Meanwhile, in the ethanol organosolv extraction process, the $G$ unit moiety in which the 
(a)

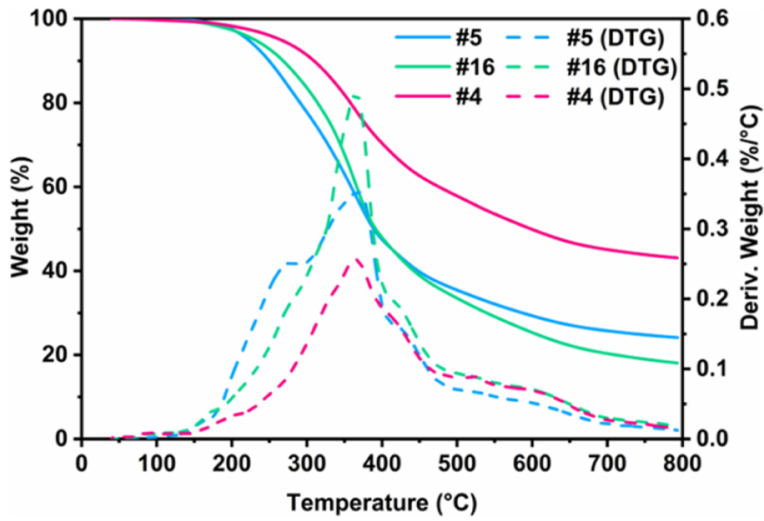

(b)

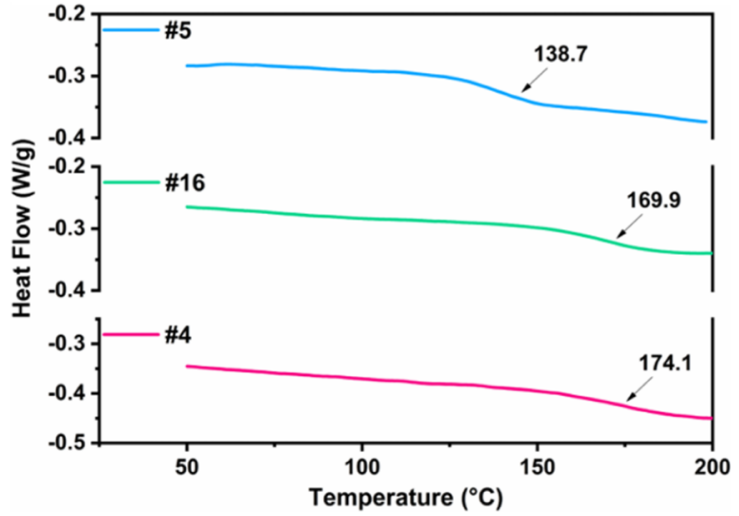

Figure 8. TGA thermal curve and DSC curve of three EOL types (\#5: EOL extracted under mild conditions, \#16: EOL extracted under moderate conditions, and \#4: EOL extracted under harsh conditions). (a) TGA thermal curve of three EOL types. (b) DSC curve of three EOL types.

C5 site of the aromatic ring was not substituted could be extracted under relatively mild conditions, and the amount of the extracted $S$ unit moiety increased as the severity of the extraction increased, resulting in a high $\mathrm{S} / \mathrm{G}$ ratio. Moreover, as shown in Table 2, as the extraction conditions were severely increased, not only the concentration of syringyl $\mathrm{OH}$ increased but also the concentration of $\mathrm{C} 5$-substituted $\mathrm{OH}$ increased. As mentioned in the Hydroxyl Group Content section, recondensation of small lignin fractions liberated from lignin macromolecules could be stimulated under severe extraction conditions, resulting in a more condensed structure.

Figure 6 shows the lignin side chain region, and from this figure, various side chain coupling structures, such as $\beta-\mathrm{O}-4$, $\beta-\beta$, and $\beta-5$, were observed. The $\beta-\mathrm{O}-4$ linkage, which is known to be the dominant linkage, was observed at the highest concentration in all three EOL types, followed by the $\beta-\beta$ and $\beta-5$ linkages. In the organosolv pretreatment, decomposition and recondensation of organosolv lignin occur simultaneously, and these reactions are greatly affected by the reaction conditions. ${ }^{16}$ The aryl-ether linkages of lignin, which are easily decomposed under acidic conditions, are cleaved in the organosolv extraction process. Some of the lignin-derived and intermediate products produced during the decomposition of lignin form a more rigid structure through recondensation, including an $\alpha$-position condensation in the side chain and a benzyl carbocation reaction in the aromatic ring. ${ }^{30}$ Therefore, concentrations of the three main coupling structures of the aryl-ether bond decreased with increasingly severe extraction conditions, and this was accompanied by a decrease in the molecular weight of the extracted EOL and the formation of a condensed structure.

Thermal Properties of EOL Depending on Its Structural Characteristics. Lignin is known to be relatively stable at high temperatures because it has a backbone structure with aromatic rings. ${ }^{11,31}$ These thermal properties of lignin are among its attractive functions in the field of bioplastics. Lignin has both thermoplastic and thermosetting properties due to its amorphous chemical structure and intra- and intermolecular interactions. ${ }^{12}$ The structural characteristics of lignin and intraand intermolecular hydrogen bonds contribute to the thermoplasticity of lignin, but the poor fluidity of lignin hinders its use as a thermoplastic resin in the bioplastic field. In addition, lignin is also considered to have thermosetting properties since it forms a cross-link at high temperatures. In this way, thermal properties of lignin macromolecules are influenced by structural characteristics, including intramolecular bonds, functional groups, and molecular weight. Although many attempts have been made to industrially utilize the properties of lignin, which include the relatively stable structure of lignin at high temperature and abundance as a natural polymer, the unpredictable thermal properties still limit its utilization. Therefore, it is important to determine which lignin structural characteristics affect the thermal properties of EOL. Figure 7 shows the correlation between the thermal decomposition behaviors and the structural characteristics of the EOLs.

As shown in Figure 7, structural characteristics of lignin influenced the thermal degradation behavior of EOLs. In particular, the models in which the weight loss rate at $300{ }^{\circ} \mathrm{C}$ was plotted against the number-average molecular weight $\left(M_{\mathrm{n}}\right)$, weight-average molecular weight $\left(M_{\mathrm{w}}\right)$, and phenolic hydroxyl group content (Phenolic OH) of the EOL have a high $R$-squared value, indicating a high correlation. In general, it is known that polymers, including starch and polylactic acid, exhibit higher thermal stability because they have a higher molecular weight, that is, a higher degree of polymerization. ${ }^{32}$ However, in this study, EOL, which has a higher molecular weight, tended to exhibit greater weight loss at $300{ }^{\circ} \mathrm{C}$. Lignin, which is a polyphenolic macromolecule, usually has various intramolecular linkages. ${ }^{33}$ In general, oxygen-containing functional groups including aryl-ether bonds are known to be chemically degradable and thermally unstable compared to saturated hydrocarbons. ${ }^{34}$ Several studies also have reported that the lignin with a condensed structure has better thermal stability. ${ }^{35}$ Therefore, the EOL with a condensed structure, in which $\mathrm{C}-\mathrm{C}$ bonds are introduced instead of ether bonds, generating hydroxyl groups on $\mathrm{C} 4$ of the aromatic ring during the extraction process, exhibited a lower weight loss rate at 300 ${ }^{\circ} \mathrm{C}$.

On the other hand, as shown in the results of the correlation between the aromatic hydroxyl group and the weight loss rate at $300{ }^{\circ} \mathrm{C}$, it was shown that the higher content of phenolic hydroxyl groups in the lignin macromolecule contributes to the thermal stability. The hydroxyl group has a relatively low thermal stability compared to other oxygen-containing functional groups, and it promotes the thermal degradation at a relatively low temperature. ${ }^{34}$ However, the condensed rigid structure of the aromatic moieties and high frequency of intermolecular hydrogen bond interactions of phenolic hydroxyl groups contribute to the thermal stability of 
(a)

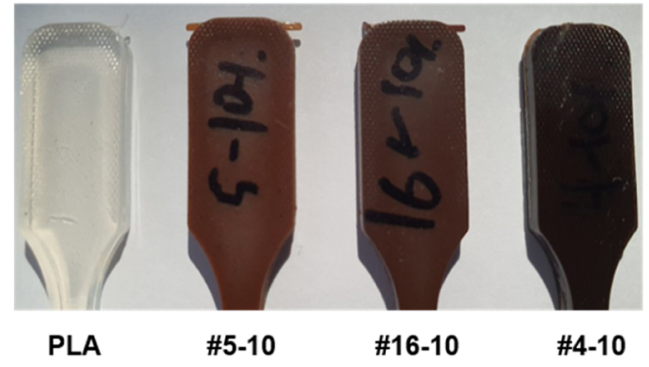

(b)

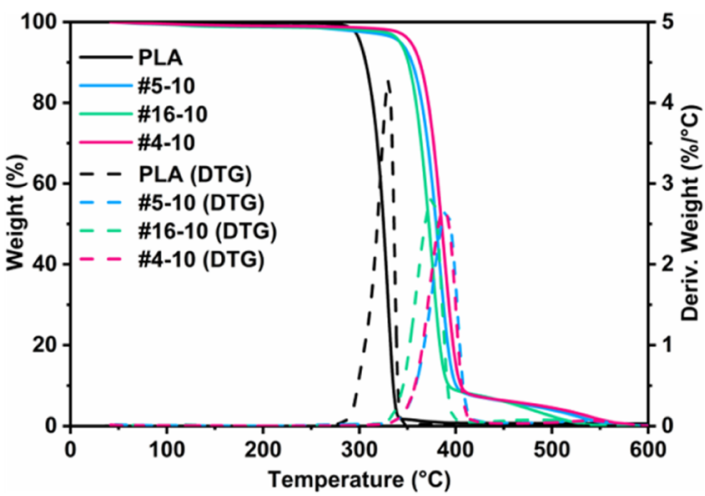

Figure 9. EOL-PLA blends (\#5-10: EOL-PLA blend with 10\% (w/w) of EOL \#5, \#16-10: EOL-PLA blends with 10\% (w/w) of EOL \#16, \#410: EOL-PLA blends with $10 \%(\mathrm{w} / \mathrm{w})$ of EOL \#4) and TGA thermal curve based on three EOL types. (a) EOL-PLA blends based on three EOL types. (b) TGA thermal curve of three blend types of EOL and neat PLA.

lignin. ${ }^{11,36}$ Therefore, the EOL with a low aliphatic hydroxyl content and a high phenolic hydroxyl content, which was extracted under severe conditions, showed a low weight loss rate at $300{ }^{\circ} \mathrm{C}$.

These results can be supplemented by the thermogravimetric analysis (TGA) thermal curve and the DSC curve of three EOL types shown in Figure 8. Three EOL types with different structural characteristics also displayed different thermal decomposition patterns. EOL \#5, which had the largest molecular weight and the highest aliphatic hydroxyl group content because of the mildest extraction conditions, showed the lowest decomposition starting temperature, derived from the low thermal stability of aliphatic hydroxyl groups. In the first derivative thermogravimetry, the initial decomposition rate was found to decrease as the extracted lignin had a smaller molecular weight and a higher phenolic hydroxyl group content. Furthermore, the char yield at $800{ }^{\circ} \mathrm{C}$ was the highest for EOL \#4. The condensed chemical structure, in which $\mathrm{C}-\mathrm{C}$ bonds are introduced instead of ether bonds, could be involved in the high char yield of EOL.

As a result of the DSC analysis, the glass transition temperature of three EOL types showed a high value, from 138.7 (\#5) to 174.1 (\#4). It is known that lignin has a higher glass transition temperature $\left(T_{\mathrm{g}}\right)$, which is one of the most significant factors that determine its thermal properties, than most synthetic materials. ${ }^{31}$ It is concluded that they have condensed rigid phenolic moieties and a high frequency of intermolecular hydrogen bond interactions. In this respect, low molecular weight lignin, which is extracted under harsh conditions, has a high $T_{\mathrm{g}}$ due to the introduction of many phenolic hydroxyl groups and the formation of a rigid phenolic structure. $^{37}$ In this way, lignin has different structural characteristics depending on the extraction conditions, and the inherent characteristics have a complex effect on the thermal properties of lignin. Therefore, it is necessary to understand the relationship between the structural characteristics and properties of lignin for the effective application of EOL.

Thermal Properties of the EOL-PLA Blends Based on Three EOL Types. The addition of lignin can significantly change the properties of PLA, such as its thermal properties, mechanical strength, and biodegradation behavior. Figure $9 \mathrm{~b}$ shows the thermal decomposition behavior of EOL-PLA blends based on three EOL types with neat PLA. The neat
PLA exhibited a very narrow decomposition temperature range between 300 and $350{ }^{\circ} \mathrm{C}$. EOL-PLA blends showed improved thermal stability compared to neat PLA. Previous studies evaluating the thermal properties using lignin-PLA blends revealed conflicting thermal decomposition properties depending on the type of lignin used. ${ }^{38-41}$ In general, organosolv lignin has high purity, is sulfur-free, and has low ash and polysaccharide contents compared to other technical lignins, including kraft and soda lignin. In particular, organosolv lignin is thermally stable at relatively high temperatures because it contains few thiols $(-\mathrm{SH})$ and sulfonic acid $\left(-\mathrm{SO}_{3} \mathrm{H}\right)$ groups, which can be easily decomposed during pyrolysis. ${ }^{42,43}$ In addition, the narrow polydispersity of EOL contributes to an even distribution within the blend.

In this study, all EOL-PLA blends with $10 \%(w / w)$ EOL had an increased starting point of thermal decomposition and increased the maximum decomposition temperature. The EOL-PLA blends exhibited similar thermal decomposition temperature ranges (from 350 to $400{ }^{\circ} \mathrm{C}$ ) and behaviors. Among the blends, the blend using EOL \#4 extracted under severe conditions had a starting point of thermal decomposition that was higher than that of the other blends and neat PLA, and it had the highest maximum decomposition temperature $\left(385.7{ }^{\circ} \mathrm{C}\right)$. This result corresponds to the thermal properties of EOL, which depend on its structural characteristics. The results of the thermal analysis of the EOLs showed that EOL \#4 had a higher starting temperature for thermal decomposition and a slower initial decomposition rate than the other two EOL types. In this respect, the blend with evenly distributed lignin \#4, which has excellent thermal stability, was considered to exhibit high heat resistance compared to the blends containing the other EOLs. Consequently, the EOL-PLA blends had improved thermal properties compared to those of neat PLA. Moreover, the EOL-PLA blends exhibited slightly different thermal properties depending on the type of lignin, and this difference became apparent as the lignin content in the blend increased. Therefore, it is important to impart desirable thermal properties within a blend by understanding the relationship between the structural characteristics and the properties of lignin. 
Table 4. Chemical Composition of Debarked Jolcham Oak

\begin{tabular}{|c|c|c|c|c|c|c|c|}
\hline & \multicolumn{3}{|c|}{ sugars } & \multicolumn{2}{|c|}{ lignin } & \multirow[b]{2}{*}{ extractives } & \multirow[b]{2}{*}{ total } \\
\hline & glucose & XMG & arabinose & Klason lignin & acid soluble lignin & & \\
\hline Jolcham oak & $45.32 \pm 0.74$ & $15.28 \pm 0.19$ & $0.88 \pm 0.03$ & $26.57 \pm 0.43$ & $3.69 \pm 0.09$ & $1.72 \pm 0.22$ & 95.43 \\
\hline
\end{tabular}

\section{CONCLUSIONS}

In conclusion, the extraction conditions (extraction temperature, sulfuric acid concentration, and ethanol concentration) have a significant effect on the structural characteristics (molecular weight and phenolic and aliphatic hydroxyl group content) of EOL within RSM analysis. EOLs with a low molecular weight and low PDI were obtained under conditions of high reaction temperature and high sulfuric acid concentration, and EOLs with high phenolic hydroxyl content were extracted under harsh extraction conditions. In addition, EOLs with a more condensed structure, which was due to the decomposition of aryl-ether linkages in the macromolecular structure, was extracted as the severity of the extraction conditions increased.

The structural characteristics of EOL derived under different extraction conditions influenced its thermal properties. In particular, the molecular weight and phenolic hydroxyl group showed a distinct correlation, and the EOL that had a low molecular weight, high phenolic hydroxyl content, and low aryl ether linkage content had a low starting temperature of thermal decomposition and a low initial decomposition rate with high $T_{\mathrm{g}}$. In a manner corresponding with the thermal properties of the EOL, the EOL-PLA blends prepared using three different EOL types exhibited improved thermal stability compared to neat PLA with slightly different thermal decomposition behaviors, depending on the EOL type used. The EOL-PLA blend prepared by using EOL \#4 had excellent thermal properties and displayed a higher starting point of thermal decomposition and maximum decomposition temperature than the other blends.

\section{MATERIALS AND METHODS}

EOL Preparation. Raw Materials. A debarked jolcham oak (Quercus serrata) was supplied by the Taehwasan Academic Forest. The logs were milled by a sawdust producer (UR-300B, Yulim Machinery, Gyeongsan, Republic of Korea), and then, the sawdust was finely ground into particles of approximately $0.5 \mathrm{~mm}$ by the Pulverisette 15 cutting mill (FRITSCH GmbH, Idar-Oberstein, Germany). The fine powders were air-dried to a moisture content of less than $5 \%$ and stored at $4{ }^{\circ} \mathrm{C}$ until used. Table 4 summarizes the chemical composition of debarked jolcham oak.

Conditions for EOL Extraction. RSM based on the central composite design (CCD) was adopted to investigate the effect of the extraction conditions on the structural characteristics of EOL. Table S4 shows the reaction conditions composed of $2^{3}$ factorial points and three central points, selected based on the results of previous studies conducted in our laboratory: reaction temperature: $160{ }^{\circ} \mathrm{C}$; sulfuric acid concentration: $1 \%$; and ethanol concentration: $60 \%$. The independent variables were set as the reaction temperature $\left(\mathrm{X} 1,{ }^{\circ} \mathrm{C}\right)$, sulfuric acid concentration (X2, \%), and ethanol concentration (X3, \%). The coded level of each run corresponded to the actual independent variable as follows (variable = value of the center point/variation of the coded level per point): reaction temperature $=160 / 20$, sulfuric acid concentration $=1 / 0.5$, ethanol concentration $=60 / 20$. The dependent variables were set as the number-average molecular weight ( $\mathrm{Y} 1, \mathrm{Da})$, weightaverage molecular weight (Y2, Da), PDI (Y3), phenolic hydroxyl group content (Y4, mmol/g), and aliphatic hydroxyl group content (Y5, $\mathrm{mmol} / \mathrm{g})$. The reaction time was fixed to 5 min as a control variable.

EOL Extraction Process. Ethanol organosolv pretreatment was conducted to dissolve lignin from the complex cell wall structure of the biomass according to an experimental matrix of 17 runs extracted from the CCD. Fifty grams of wood powder was loaded with $400 \mathrm{~mL}$ of solvent prepared to depend on each run's reaction conditions. The ethanol organosolv pretreatment was carried out using a $1000 \mathrm{~mL}$-capacity batch type reactor. The reactor was heated to the target temperature for $40 \mathrm{~min}$ and then maintained for $5 \mathrm{~min}$. After the reaction was completed, the reactor was quenched to $60^{\circ} \mathrm{C}$ using an ice chamber. The liquid fraction was collected by solid-liquid separation with filter paper (no. 52, Hyundai Micro Co., Seoul, Republic of Korea).

An 8-fold dilution of the liquid fraction was prepared with deionized water to precipitate the EOL, and the suspension was allowed to stabilize for $24 \mathrm{~h}$. The precipitated lignin was separated from the liquid fraction using the same filter paper as was used for the solid-liquid separation and lyophilized for 72 h. The EOL yield was calculated as follows: EOL yield (\%) = EOL obtained $(\mathrm{g})$ in the filtrate/lignin content $(\mathrm{g})$ in the ovendried raw material $\times 100$.

Chemical Composition of the Liquid Hydrolysate Analysis. The liquid hydrolysate was hydrolyzed for the determination of the monomeric sugars-derived cellulose and hemicellulose. After recovery of the EOL, the remaining liquid hydrolysate was adjusted to $4 \%$ sulfuric acid concentration. The solution was reacted for $1 \mathrm{~h}$ at $121^{\circ} \mathrm{C}$ using an autoclave. The solution was filtered by using a $0.45 \mu \mathrm{m}$ polytetrafluoroethylene (PTFE) filter (ADVANTEC Co., Japan). The monomeric sugars [glucose, XMG (xylose, mannose, and galactose), and arabinose] were determined using a highperformance liquid chromatography system (Ultimate 3000, Dionex, USA), equipped with an Aminex 87H column (300 $\mathrm{mm} \times 7.8 \mathrm{~mm}$, Bio-Lad Laboratories, USA).

Characterization of EOL. Molecular Weight. The acetylation of the EOL was determined to analyze the molecular weight. Fifty milligrams EOL was reacted with an acetic anhydride-pyridine $(1: 1, \mathrm{v} / \mathrm{v})$ mixture at $105^{\circ} \mathrm{C}$ for $2 \mathrm{~h}$. After the reaction was complete, the acetylated EOL was collected by dropping in deionized water. Five milligrams acetylated EOL was dissolved in $1 \mathrm{~mL}$ of tetrahydrofuran. The sample was filtered by a $0.45 \mu \mathrm{m}$ PTFE filter (ADVANTEC Co., Japan). After preparation of the sample, number-average molecular weight $\left(M_{\mathrm{n}}\right)$, weight-average molecular weight $\left(M_{\mathrm{w}}\right)$, and PDI were analyzed by a gel permeation chromatography system (Nexera LC-40, Shimadzu, Japan), equipped with an SDV 1000A $5 \mu \mathrm{m} 8 \times 300 \mathrm{~mm} \mathrm{~S} / \mathrm{N}$ 91112605 column. The mobile phase flow rate was $1 \mathrm{~mL} / \mathrm{min}$. The calibration curves were set using 12 polystyrene standards with a range of molecular weights from 266 to $62,500 \mathrm{Da}$. 
Hydroxyl Group Content. The hydroxyl group content of the EOL was determined by ${ }^{31} \mathrm{P}$ NMR spectroscopy, as described in previous studies. Pyridine and deuterated chloroform were mixed to prepare a solvent solution $[1.6: 1(\mathrm{v} / \mathrm{v})]$. A mixture solution was prepared by adding 100 $\mathrm{mg}$ cyclohexanol (internal standard) and $90 \mathrm{mg}$ chromium acetylacetonate (relaxation reagent) to $25 \mathrm{~mL}$ of the solvent solution. Approximately $20 \mathrm{mg}$ lignin was accurately weighed and placed in a $4 \mathrm{~mL}$ vial. A total of $400 \mu \mathrm{L}$ of the solvent solution and $150 \mu \mathrm{L}$ of the mixture solution were used to dissolve the EOL. The mixture was stirred for $5 \mathrm{~min}$. After mixing, $70 \mu \mathrm{L}$ of 2-chloro-4,4,5,5-tetramethyl-1,2,3-dioxaphospholane was introduced into the mixture as a phosphorylating reagent. The mixture was blended with a vortex mixer for a few seconds. The completely prepared samples were transferred to a 5-mm NMR tube for analysis by ${ }^{31} \mathrm{P}$ NMR spectroscopy. The ${ }^{31} \mathrm{P}$ NMR spectra of the EOL from 17 runs were obtained using a $600 \mathrm{MHz}$ NMR spectrometer (ADVANCE 600, Bruker, Germany), equipped with a $14.095 \mathrm{~T}$ superconducting $51 \mathrm{~mm}$ bore magnet and $5 \mathrm{~mm}$ BBO BB-H\&F-D CryoProbe Prodigy.

Intramolecular Coupling Structure of EOL. The intramolecular coupling structure of EOL was investigated using quantitative 2D-HSQC NMR spectroscopy. Quantitative 2DHSQC NMR spectroscopy was performed using a $600 \mathrm{MHz}$ NMR spectrometer (ADVANCE 600, Bruker, Germany). Fifty milligrams EOL was prepared by dissolving it in DMSO- $d_{6}$ for analysis. Each HSQC experiment was preformed using Bruker's "hsqcetgpsisp2.2" pulse program with the following parameters: a $90^{\circ}$ pulse, $0.08 \mathrm{~s}$ acquisition time, $2.0 \mathrm{~s}$ pulse delay, $1 \mathrm{JC}-\mathrm{H}$ at $150 \mathrm{~Hz}, 48$ scans, and acquisition of 1024 data points (for ${ }^{1} \mathrm{H}$ ) over 512 increments (for ${ }^{13} \mathrm{C}$ ). Data processing and analysis were performed using MestReNova v6.0 software. The coupling structure of the EOL sample according to HSQC spectroscopy was determined by correlating the data from the databases cited in the literature. ${ }^{44,45}$ The C9 unit ( $\mathrm{S}$ unit and G unit) in aromatic/unsaturated $(\delta \mathrm{C} / \delta \mathrm{H} \quad 100-125 / 6.5-7.5)$ regions and the coupling structure $(\beta-\mathrm{O}-4, \beta-\beta$, and $\beta-5)$ in the oxygenated aliphatic side chain $(\delta \mathrm{C} / \delta \mathrm{H} 50-90 / 2.5-6.0)$ regions were determined by a quantitative method based on the 2D-HSQC spectra, using aromatic units as internal standards. $^{44}$ The internal standard (C9) and coupling structures $\left(I_{\mathrm{x}} \%\right)$ are calculated as shown in eqs 1 and 2

$$
\begin{aligned}
& \text { C9 }=0.5\left(S+S^{\prime}\right)+G \\
& I_{\mathrm{x}} \%=\frac{I_{\mathrm{x}}}{I_{\mathrm{C} 9}} \times 100
\end{aligned}
$$

$I_{\mathrm{x}}$ is obtained as the integral value of the $\alpha$-position of $\beta$-O-4, $\beta-\beta$, and $\beta-5$.

Thermal Decomposition Characteristics of EOL. The thermal decomposition characteristics of the EOL obtained from 17 runs was analyzed by a thermogravimetric analyzer (Discovery TGA, TA Instruments, USA). Approximately 10 mg sample was scanned from 25 to $800{ }^{\circ} \mathrm{C}$ at a constant heating rate of $10{ }^{\circ} \mathrm{C} / \mathrm{min}$. After reaching the target temperature, the furnace was cooled in a high-quality nitrogen inert atmosphere with a $50 \mathrm{~mL} / \mathrm{min} \mathrm{N}_{2}$ flow.

Glass Transition Temperature of EOL. The glass transition temperatures of three EOL types were investigated using a differential scanning calorimeter (Discovery DSC, TA instruments, USA). DSC analysis was conducted in the temperature range from -25 to $250^{\circ} \mathrm{C}$ under high-quality nitrogen flow.
The first heating scan was conducted in the temperature range from 25 to $200{ }^{\circ} \mathrm{C}$ at a heating rate of $10{ }^{\circ} \mathrm{C} / \mathrm{min}$, and the target temperature was held for 2 min to exclude the thermal history of the EOLs. Then, the temperature of the furnace was decreased to $-25{ }^{\circ} \mathrm{C}$ and held for $10 \mathrm{~min}$. For the second heating scan, the temperature was heated from -25 to $250{ }^{\circ} \mathrm{C}$ at the same heating rate as used in the first scan. The glass transition temperatures of the EOLs were determined by the second heating scan data.

EOL-PLA Blend. Preparation of Melting Blends of EOL and PLA. EOL-PLA blends with three EOL types were manufactured. EOL and PLA (2003D, NatureWorks, USA) were mechanically mixed and melted at various mixing ratios $(0,1,5$, and $10 \%(w / w)$ of EOL in the EOL-PLA blend) using a specimen molding machine (KP-M2100H, Kipae, Republic of Korea). The following operating conditions were the same for all samples: $200{ }^{\circ} \mathrm{C}$ operating temperature, $5 \mathrm{~min}$ operation time, and $100 \mathrm{rpm}$. Then, the blends were injected to mold a specimen for the tensile strength test.

Thermal Decomposition Characteristics of EOL-PLA Blends. The thermal decomposition characteristics of the EOL-PLA blends were analyzed in the same manner as described in the thermal decomposition characteristics of EOL.

\section{ASSOCIATED CONTENT}

\section{Supporting Information}

The Supporting Information is available free of charge at https://pubs.acs.org/doi/10.1021/acsomega.0c05234.

Statistical analysis of variance for EOL molecular weight models, PDI, and hydroxyl content models and central composite design for RSM (PDF)

\section{AUTHOR INFORMATION}

\section{Corresponding Author}

In-Gyu Choi - Department of Agriculture, Forestry, and Bioresources and Research Institute of Agriculture and Life Sciences, Seoul National University, Seoul 08826, Republic of Korea; 10 orcid.org/0000-0001-5604-6823; Phone: +82-2880-4785; Email: cingyu@snu.ac.kr; Fax: +82-2-873-2318

\section{Authors}

June-Ho Choi - Department of Forest Sciences, Seoul National University, Seoul 08826, Republic of Korea

Seong-Min Cho - Department of Forest Sciences, Seoul National University, Seoul 08826, Republic of Korea

Jong-Chan Kim - Department of Agriculture, Forestry, and Bioresources, Seoul National University, Seoul 08826, Republic of Korea

Sang-Woo Park - Department of Agriculture, Forestry, and Bioresources, Seoul National University, Seoul 08826, Republic of Korea

Young-Min Cho - Department of Agriculture, Forestry, and Bioresources, Seoul National University, Seoul 08826, Republic of Korea

Bonwook Koo - Green and Sustainable Materials R\&D Department, Korea Institute of Industrial Technology (KITECH), Cheonan 31056, Republic of Korea

Hyo Won Kwak - Department of Agriculture, Forestry, and Bioresources, Seoul National University, Seoul 08826, Republic of Korea

Complete contact information is available at: https://pubs.acs.org/10.1021/acsomega.0c05234 


\section{Notes}

The authors declare no competing financial interest.

\section{ACKNOWLEDGMENTS}

This study was carried out with the support of the "Mid-career Researcher Program in Basic Research (2019R1A2C1005369)" provided by the National Research Foundation of Korea (Ministry of Science and ICT) and the "R\&D Program for Forest Science Technology (2020256A002021-0001)" provided by Korea Forest Service (Korea Forestry Promotion Institute).

\section{REFERENCES}

(1) Garside, M. Global plastic production 1950-2018; Statista, 2019.

(2) Verma, R.; Vinoda, K. S.; Papireddy, M.; Gowda, A. N. S. Toxic pollutants from plastic waste-a review. Procedia Environ. Sci. 2016, 35, 701-708.

(3) Sajjan, A. M.; Naik, M. L.; Kulkarni, A. S.; Fazal-E-Habiba Rudgi, U.; M, A.; Shirnalli, G. G.; A, S.; Kalahal, P. B. Preparation and characterization of PVA-Ge/PEG-400 biodegradable plastic blend films for packaging applications. Chem. Data Collect. 2020, 26, 100338 .

(4) Chanprateep, S. Current trends in biodegradable polyhydroxyalkanoates. J. Biosci. Bioeng. 2010, 110, 621-632.

(5) Mostafa, N. A.; Farag, A. A.; Abo-dief, H. M.; Tayeb, A. M. Production of biodegradable plastic from agricultural wastes. Arabian J. Chem. 2018, 11, 546-553.

(6) Kumar, A.; Tumu, V. R. Physicochemical properties of the electron beam irradiated bamboo powder and its bio-composites with PLA. Composites, Part B 2019, 175, 107098.

(7) Yang, J.; Ching, Y.; Chuah, C. Applications of lignocellulosic fibers and lignin in bioplastics: A review. Polymers 2019, 11, 751.

(8) Ganewatta, M. S.; Lokupitiya, H. N.; Tang, C. Lignin Biopolymers in the Age of Controlled Polymerization. Polymers 2019, 11, 1176.

(9) Sen, S.; Patil, S.; Argyropoulos, D. S. Thermal properties of lignin in copolymers, blends, and composites: a review. Green Chem. 2015, 17, 4862-4887.

(10) Duval, A.; Lawoko, M. A review on lignin-based polymeric, micro-and nano-structured materials. React. Funct. Polym. 2014, 85, 78-96.

(11) Brodin, I.; Sjöholm, E.; Gellerstedt, G. The behavior of kraft lignin during thermal treatment. J. Anal. Appl. Pyrolysis 2010, 87, 7077.

(12) Jeong, H.; Park, J.; Kim, S.; Lee, J.; Ahn, N.; Roh, H.-g. Preparation and characterization of thermoplastic polyurethanes using partially acetylated kraft lignin. Fibers Polym. 2013, 14, 1082-1093.

(13) Cui, C.; Sadeghifar, H.; Sen, S.; Argyropoulos, D. S. Toward thermoplastic lignin polymers; part II: thermal \& polymer characteristics of kraft lignin \& derivatives. BioResources 2013, 8, 864-886.

(14) Baumberger, S.; Abaecherli, A.; Fasching, M.; Gellerstedt, G.; Gosselink, R.; Hortling, B.; Li, J.; Saake, B.; de Jong, E. Molar mass determination of lignins by size-exclusion chromatography: towards standardisation of the method. Holzforschung 2007, 61, 459-468.

(15) McDonough, T. J. The chemistry of organosolv delignification; The Institute of Paper Science and Technology, 1992.

(16) Zhao, X.; Li, S.; Wu, R.; Liu, D. Organosolv fractionating pretreatment of lignocellulosic biomass for efficient enzymatic saccharification: chemistry, kinetics, and substrate structures. Biofuels, Bioprod. Biorefin. 2017, 11, 567-590.

(17) Choi, J.-H.; Jang, S.-K.; Kim, J.-H.; Park, S.-Y.; Kim, J.-C.; Jeong, H.; Kim, H.-Y.; Choi, I.-G. Simultaneous production of glucose, furfural, and ethanol organosolv lignin for total utilization of high recalcitrant biomass by organosolv pretreatment. Renewable energy 2019, 130, 952-960.

(18) Chalermsaktrakul, T.; Matsumura, Y. Effect of acetic acid addition on decomposition of xylose in supercritical water. Energy Fuels 2018, 32, 1754-1760.
(19) Laurichesse, S.; Avérous, L. Chemical modification of lignins: Towards biobased polymers. Prog. Polym. Sci. 2014, 39, 1266-1290.

(20) Sannigrahi, P.; Ragauskas, A. J.; Miller, S. J. Lignin structural modifications resulting from ethanol organosolv treatment of loblolly pine. Energy Fuels 2010, 24, 683-689.

(21) Tirtowidjojo, S.; Sarkanen, K. V.; Pla, F.; McCarthy, J. L. Kinetics of organosolv delignification in batch-and flow-through reactors. Holzforschung 1988, 42, 177-184.

(22) Gilarranz, M. A.; Rodríguez, F.; Oliet, M. Lignin behavior during the autocatalyzed methanol pulping of eucalyptus globulus changes in molecular weight and functionality. Holzforschung 2000, 54, 373-380.

(23) Pan, X.; Arato, C.; Gilkes, N.; Gregg, D.; Mabee, W.; Pye, K.; Xiao, Z.; Zhang, X.; Saddler, J. Biorefining of softwoods using ethanol organosolv pulping: Preliminary evaluation of process streams for manufacture of fuel-grade ethanol and co-products. Biotechnol. Bioeng. 2005, 90, 473-481.

(24) Goyal, G. C.; Lora, J.; Pye, E. Autocatalyzed organosolv pulping of hardwoods: effect of pulping conditions on pulp properties and characteristics of soluble and residual lignin. Tappi J. 1992, 75, 110116.

(25) El Hage, R.; Brosse, N.; Sannigrahi, P.; Ragauskas, A. Effects of process severity on the chemical structure of Miscanthus ethanol organosolv lignin. Polym. Degrad. Stab. 2010, 95, 997-1003.

(26) Du, L.; Wang, Z.; Li, S.; Song, W.; Lin, W. A comparison of monomeric phenols produced from lignin by fast pyrolysis and hydrothermal conversions. Int. J. Chem. React. Eng. 2013, 11, 135145 .

(27) Liu, W.-J.; Jiang, H.; Yu, H.-Q. Thermochemical conversion of lignin to functional materials: a review and future directions. Green Chem. 2015, 17, 4888-4907.

(28) Zakzeski, J.; Bruijnincx, P. C. A.; Jongerius, A. L.; Weckhuysen, B. M. The catalytic valorization of lignin for the production of renewable chemicals. Chem. Rev. 2010, 110, 3552-3599.

(29) Li, M.; Foster, C.; Kelkar, S.; Pu, Y.; Holmes, D.; Ragauskas, A.; Saffron, C. M.; Hodge, D. B. Structural characterization of alkaline hydrogen peroxide pretreated grasses exhibiting diverse lignin phenotypes. Biotechnol. Biofuels 2012, 5, 38.

(30) Wayman, M.; Lora, J. H. Simulated autohydrolysis of aspen milled wood lignin in the presence of aromatic additives: Structural modifications. J. Appl. Polym. Sci. 1980, 25, 2187-2194.

(31) Irvine, G. M. The significance of the glass transition of lignin in thermomechanical pulping. Wood Sci. Technol. 1985, 19, 139-149.

(32) Ahmed, J.; Zhang, J.-X.; Song, Z.; Varshney, S. K. Thermal properties of polylactides. J. Therm. Anal. Calorim. 2009, 95, 957964.

(33) Vanholme, R.; Demedts, B.; Morreel, K.; Ralph, J.; Boerjan, W. Lignin biosynthesis and structure. Plant Physiol. 2010, 153, 895-905.

(34) Li, L.; Yao, X.; Li, H.; Liu, Z.; Ma, W.; Liang, X. Thermal stability of oxygen-containing functional groups on activated carbon surfaces in a thermal oxidative environment. J. Chem. Eng. Jpn. 2014, 47, 21-27.

(35) Kim, J.-Y.; Hwang, H.; Oh, S.; Kim, Y.-S.; Kim, U.-J.; Choi, J. $\mathrm{W}$. Investigation of structural modification and thermal characteristics of lignin after heat treatment. Int. J. Biol. Macromol. 2014, 66, 57-65.

(36) Yoshida, H.; Mörck, R.; Kringstad, K. P.; Hatakeyama, H. Kraft lignin in polyurethanes I. Mechanical properties of polyurethanes from a kraft lignin-polyether triol-polymeric MDI system. J. Appl. Polym. Sci. 1987, 34, 1187-1198.

(37) Thakur, V. K.; Thakur, M. K.; Raghavan, P.; Kessler, M. R. Progress in green polymer composites from lignin for multifunctional applications: a review. ACS Sustainable Chem. Eng. 2014, 2, 10721092.

(38) Anwer, M. A. S.; Naguib, H. E.; Celzard, A.; Fierro, V. Comparison of the thermal, dynamic mechanical and morphological properties of PLA-Lignin \& PLA-Tannin particulate green composites. Composites, Part B 2015, 82, 92-99. 
(39) Domenek, S.; Louaifi, A.; Guinault, A.; Baumberger, S. Potential of lignins as antioxidant additive in active biodegradable packaging materials. J. Polym. Environ. 2013, 21, 692-701.

(40) Gordobil, O.; Egüés, I.; Llano-Ponte, R.; Labidi, J. Physicochemical properties of PLA lignin blends. Polym. Degrad. Stab. 2014, 108, 330-338.

(41) Li, J.; He, Y.; Inoue, Y. Thermal and mechanical properties of biodegradable blends of poly (L-lactic acid) and lignin. Polym. Int. 2003, 52, 949-955.

(42) Lin, X.; Sui, S.; Tan, S.; Pittman, C.; Sun, J.; Zhang, Z. Fast pyrolysis of four lignins from different isolation processes using PyGC/MS. Energies 2015, 8, 5107-5121.

(43) Han, T.; Sophonrat, N.; Evangelopoulos, P.; Persson, H.; Yang, W.; Jönsson, P. Evolution of sulfur during fast pyrolysis of sulfonated Kraft lignin. J. Anal. Appl. Pyrolysis 2018, 133, 162-168.

(44) Wen, J.-L.; Sun, S.-L.; Xue, B.-L.; Sun, R.-C. Recent advances in characterization of lignin polymer by solution-state nuclear magnetic resonance (NMR) methodology. Materials 2013, 6, 359-391.

(45) Constant, S.; Wienk, H. L. J.; Frissen, A. E.; Peinder, P. d.; Boelens, R.; Van Es, D. S.; Grisel, R. J. H.; Weckhuysen, B. M.; Huijgen, W. J. J.; Gosselink, R. J. A.; Bruijnincx, P. C. A. New insights into the structure and composition of technical lignins: a comparative characterisation study. Green Chem. 2016, 18, 2651-2665. 